\title{
Issues in the National Supply Policy of Nepal
}

\author{
Laxmi Panta (Wagle), Ph.D. \\ Associate Professor, Tribhuvan University, Patan Multiple Campus, Nepal \\ Correspondence: laxmipant258@gmail.com
}

\begin{abstract}
Rationality of public policy analysis emerges due to the need of understanding the nature of policies and their elements towards solving societal problems. National supply policy is formulated and implemented for the regular supply of necessary goods and services in the country. Effective implementation of the policy depends on its structure as well as on the external factors from the prevailing situation in the country. In the present article an attempt has been made to highlight the basic features of the current national supply policy of Nepal and discuss the issues related with its effective implementation. Despite several elements proposed in the policy only few have the result oriented features. Many of the elements are ambitious as well as vague. Imperfection in policy implementation witnessed during the suddenly arrived difficulties as well as at the normal time. From the discussion it has been concluded that the policy has weaknesses in its structure, basically in maintenance of hierarchy of objectives and has been facing several unsolved practical issues.
\end{abstract}

Key words: Conflicts in policy objectives, Decomposition of policy elements, Hierarchy of policy objectives, Policy linkages

\section{INTRODUCTION}

The rationality of the analysis of any public policy emerges due to several reasons as to understand the government's orientation towards the solutions to the societal problems, policy statements, objectives, instruments, and programs to be adopted towards the solutions, public expectations, and social/environmental realities and so on. Sometimes the policy situations pose serious problems that the ambitious and unclear policy statements could not be effectively implemented and there would be a least impact on the targeted problem areas. It means that there could be a mismatch between policy demand, policy decisions, policy statements, policy outputs and policy outcomes. (For detail see Reejal, 2003). So, policy analysis would be needed first, to study the nature of policy aims and objectives; second, to study the policy instruments towards the achievement of those objectives; and third, the real impact by the implementation of those instruments on the targeted areas where the problems exist. 
There are several approaches of policy analysis. First, the internal construct of the policy, also called the content is important to analyze to know the strength of finding the problem area/s, developing instruments and implementing them effectively. Second, it is necessary to analyze the impact of policy implementation on to the targeted or problem area/s. Among the several approaches, the diagnostic approach is thought to be appropriate to show the factors that explain the good and bad functioning of public policies in terms of public administration production and with respect to the efficacy of its policies and their products. It also explains the output of public services and their impacts effectively (Knopfel et al, 2007).

Public policies vary in their size and scope. Those policies may cover the entire whole of the functioning of the public administration or may be any sector specific. Their structure and implementation may depend on their scopes and sizes. Policy science itself is a normative area of study and analysis. Therefore, personal, organizational or entire governmental value judgments are natural to prevail in the study and analysis of public policies.

National supply policy of any country is closely related with other sectoral and macroeconomic policies. Sometimes by the term supply policy it may mean the policy related with the maximization of production and minimization of the costs. However, here the present context is the policy related with the matter of supplies of must necessary goods and services to the public. In this sense it is related to the supply chain management instead to the relationship between input, costs, output and their relationships. It is more closely related with the trade, agricultural, industrial and services policies. For a responsible government of any country, supply of essential goods and services in sufficient quantity in an uninterrupted manner to the general people would be among the prime responsibilities first to be fulfilled. As basic necessaries are connected with the lives of the general people, there should not be any compromise on the supply of such goods and services. The matter should be above from any political, ethnical, social or any other agenda. There should not be any adverse effects on the supply chain of essential goods and services by any of the agitations of any name and color created by internal or external factors. However, nowadays, it has been realized that time to time obstructions on the regular supply of essential goods and services has been the general rule worldwide.

In order to address the national supply problems of necessary goods and services, governments of respective countries formulate national supply policies or the national supply chain management policies. Effective implementation of the policies depends not only on their internal structures and other related domestic factors but also the factors which are created abroad. In the case of small landlocked countries like Nepal, 
both the types of factors create obstructions in the course of any national policy implementation and supply policy is more sensitive than others.

This article is an attempt to discuss the features of the 2069 B.S. (2012 A.D.) national supply policy of Nepal, analyze its components, its linkages with other related policies and the issues related to its implementation. Prior to the formulation of the policy, no other comprehensive supply policy has been formulated in the country. However, other related laws, rules and acts were in effect to address the supply chain management problem. Among those important were 'Necessary Services Regulation Law (2014 B.S.); Necessary Materials Control Law (2017 B.S.); Patent Design and Trade Mark Law (2022 B.S.); Food Law (2023 B.S.); Medicine Law (2035 B.S.); Nepal Standards Law (2037 B.S.); Nepal Standard Certification Law (2037 B.S.); Local Administration Law (2028 B.S.); Pesticides Law (2047 B.S.); Consumer Protection Law (2054 B.S.) and Promotion of Competition and Market Protection Law (2063 B.S.)' etc (GoN, 2069 B.S.). So, the current policy is the first one of the nature.

This study has followed the qualitative method of interpretation based on the available literature on policy science and secondary sources of materials on the subject have been used. It is an issue based analysis. Therefore, the endeavor has been to shed light on the gap between what the policy intends to do and what actually been its outcome or impact in the real target field. Because the gaps between policies decision, their goals, objectives, instruments and their implementation keep vital meaning. Policy not properly implemented as per the policy decisions, goals/objectives creates serious problems in the related field. "If the intended changes on target groups do not occur, something is wrong" (Sapru, 1998). So, it would be important to assess whether the policies actually achieved what they are intended to achieve.

In order to show the effectiveness the supply policy of Nepal, first of all the content of the policy has been analyzed. Then the decomposition of the objectives has been done. The decomposed policy objectives have been grouped as per their nature with the relation of the particular objectives so that the meaningful outcomes may arise by their implementation. After this the effectiveness of the policy has been assessed by the impact experienced in the targeted real field with available secondary materials especially in context to the suddenly experienced emergencies by the Nepalese society.

\section{MAJOR FEATURES OF THE POLICY}

The major features of the policy have been enumerated on the basis of the published policy document of the government ( $\mathrm{GoN}$, Ministry of Industries, Commerce and Supplies, 2069 B.S.). 


\section{The Context}

The supply policy is generally formulated and implemented by the government keeping in view the current supply situation as well as the aggregated demand of the general people, institutions and the government itself. Since market in the developing countries could not be found to function perfectly, government must take initiations in the aggregate supply matters in order to check the several adversities created by market imperfections. In such a situations government initiations would be inevitable in the supply of basic necessary goods and services. Even in the developed countries where market is comparatively developed, governments used to take initiatives in the supply of critically necessary goods and services. Therefore, contextually, it could be maintained that the policy has come as per the current needs of the economy.

\section{The Goal and Objectives of the Policy}

The supply policy has been formulated with the major goal to protect consumer rights and welfare by regular supply of must necessary goods and services of quality in reasonable prices'.It includes the objectives as to: Promote competitiveness, protect consumers' rights and welfare, maintain qualities of the must necessaries, manage national food security system, determine prices of goods and services on the basis of the real cost of production, develop integrated supply system for poor and remote food deficit areas, control artificial scarcity, black marketing and non-competitive market activities. In order to fulfill the stated objectives, the policy has been proposed to be implemented with joint collaboration of the public, private and the cooperatives sectors.

\section{Conflicts in the Objectives}

Generally objectives of the policy seem to be ideal. However, a critical observation from the practical points of view conflicts could be found within the objectives. Firstly, the twin objectives of promoting market competitiveness and protecting consumer rights and welfare are not mutually consistent as they cannot be implemented simultaneously. The phrase 'promotion of market competitiveness' conveys that currently the market structure is imperfect and is in the transitional phase. Under the imperfect market conditions in transition consumers are victimized in one or the other ways. Secondly, to maintain the quality of goods and services has been the burning issue in the present day world. It requires highly efficient, committed and powerful private and public institutions to monitor the market with good governance at the background for support. Thirdly, the concept of food security system is a new concept in most of the developing countries like Nepal. It requires vigorous efforts to establish and stabilize the food security system which may not keep coherence with other policies, the prevailing market conditions, and the supply and price systems. 
Fourthly, where market is imperfect, government has to play roles by providing different types incentives to make the market competitive, where there is not perfect cost accounting system and there is not any rule to fix the prices and how the prices of goods and services be determined on the basis of the real cost of production? When the prices of domestically produced goods and services could not be determined on the basis of real cost of production, how the same rule would be applied to the imported goods and services? Lastly, to control black marketing, artificial scarcity and other non-competitive market activities, an efficient and committed supervisory institutional mechanism with strong and good governance at the background to support would be needed which is lacking currently in most of the least developed countries like Nepal.

In short, the policy objectives desired to fulfill should have a close coherence with other domestic policies like industrial, agricultural, trade and commercial, fiscal, monetary and others. In the Nepalese context, where most of the domestic demand is being supplied by imports, and import is problematic with different types obstructions repeatedly, domestic supply system is generally dragged by trade policy especially, import policy. Current trade policy has the goal towards export promotion and diversification which rarely concerns domestic supply system. Further, maintenance of cordial trade relation with the transit country, India has always remained the vital issue since the long past. It would remain vital and would play roles in supply chain management in Nepal in the future. While framing supply policy it must be kept in mind by the policymakers and think how the forthcoming issues would be faced.

\section{DECOMPOSITION OF POLICY ELEMENTS}

One of the issue that this article aims to analyse is the decomposition of policy elements from basic policy, strategies and action policies. Therefore, in order to fulfill the goal and objectives described in the previous section, this paper proposes several options under the policy, strategy and action policy that seem to be adopted under the central executive and monitoring authorities. Here, an endeavor has been made to decompose the options focusing on the core aspects of each from the point of view of policy implementation and their impact to the targeted sectors.

The decomposition of the options has been done applying syntactical method by rephrasing them (Agnihotry, 1995) as shown in Table 1. The decomposed policy elements or options facilitate to link aim, objectives, strategies and action policies and evaluate their impact in reality. Though, each policy option may be related with more than one objective in one or the other way, the elements which are directly and more closely related to a particular objective have been put together. It has been assumed that the particular objective would be effectively achieved if those group of elements could be properly implemented. 


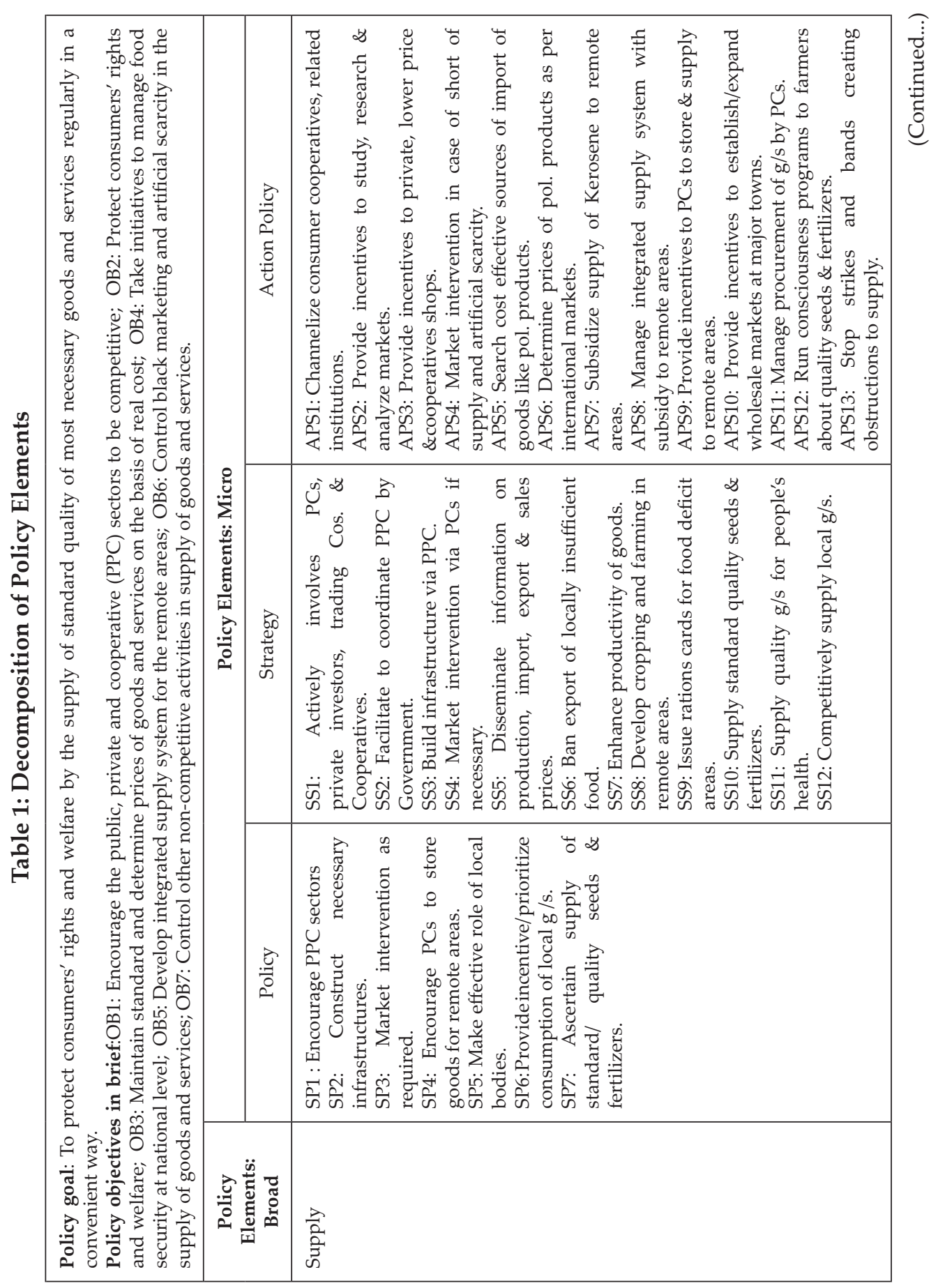




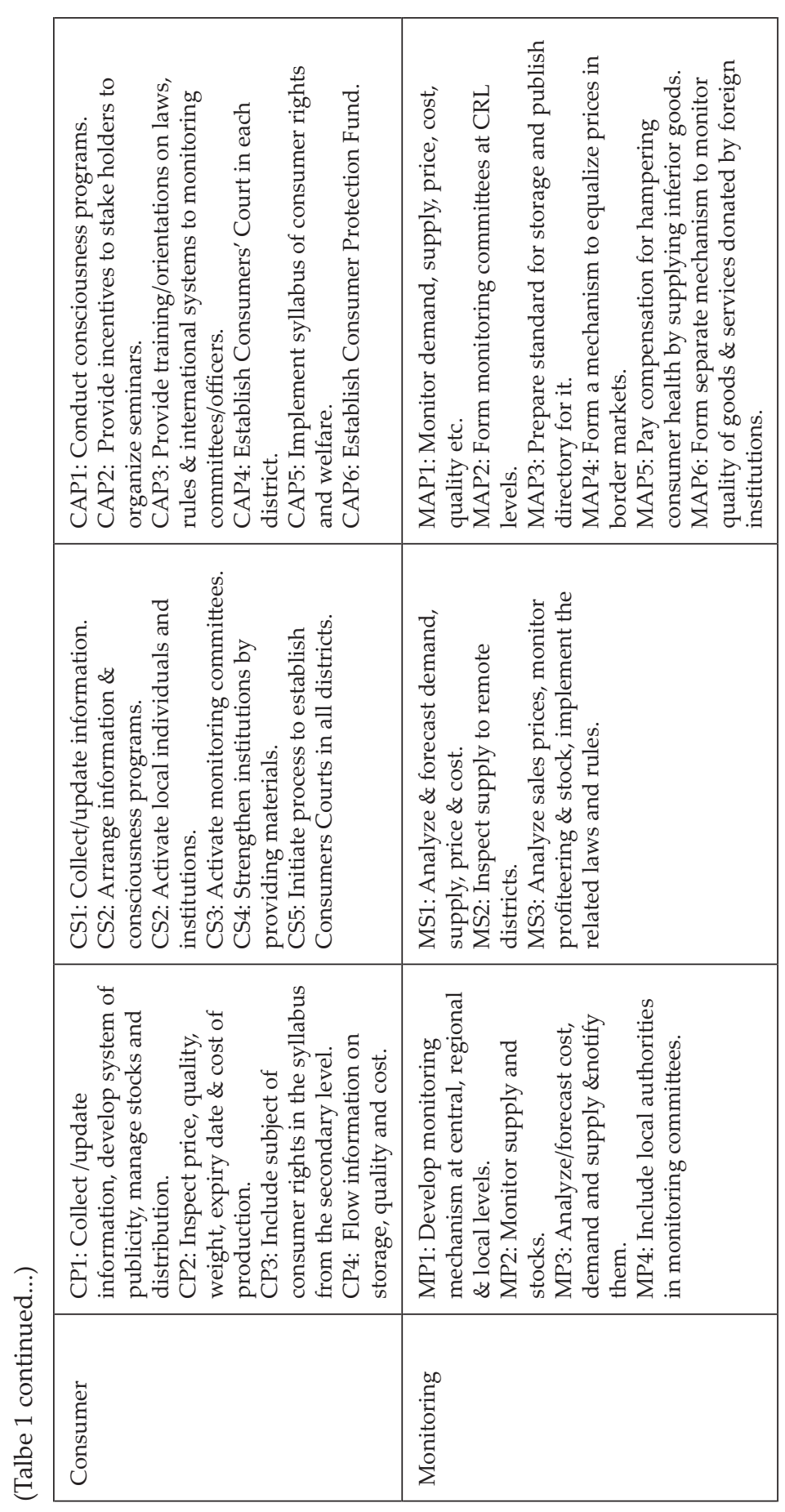




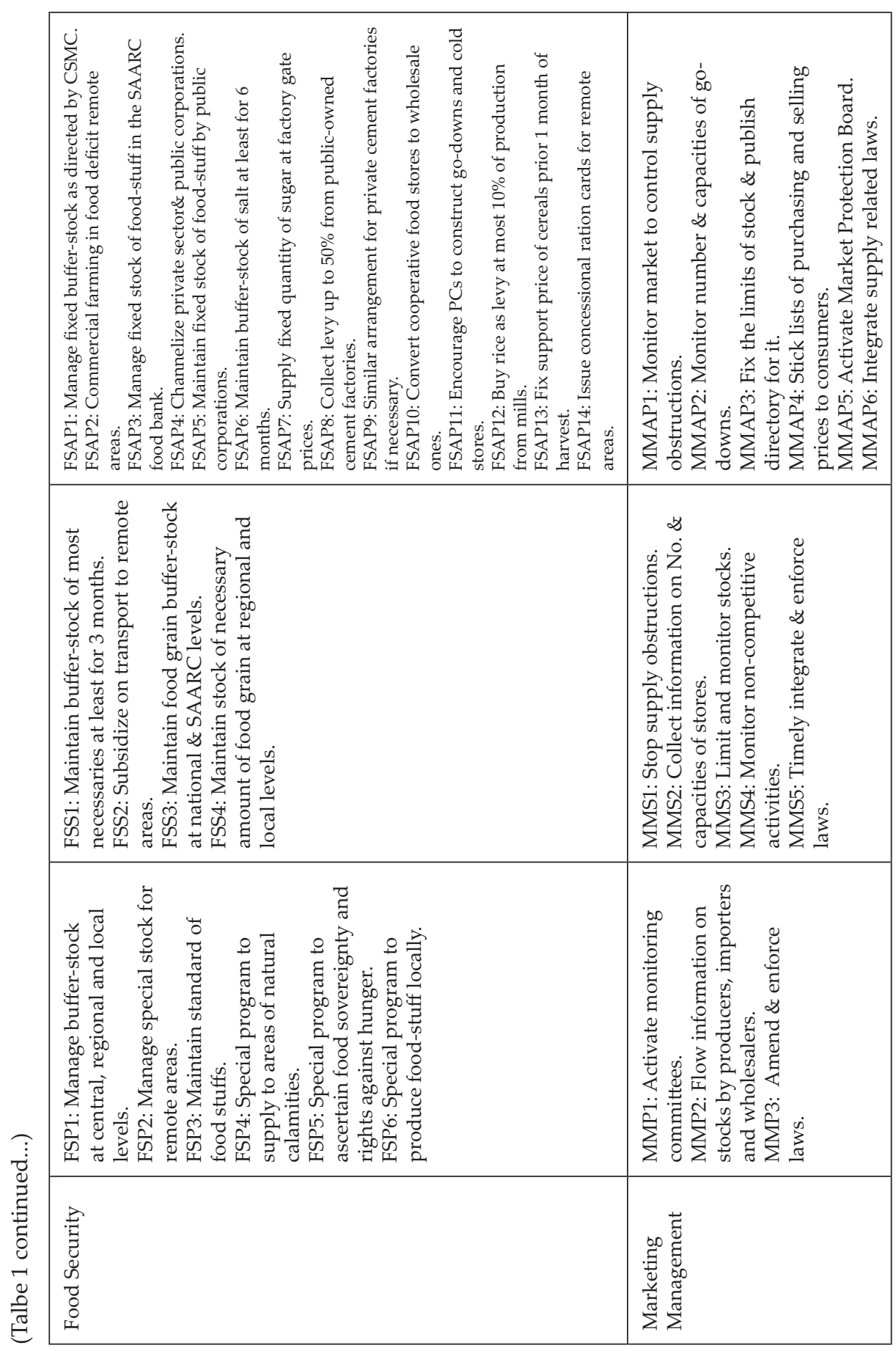

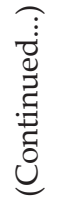




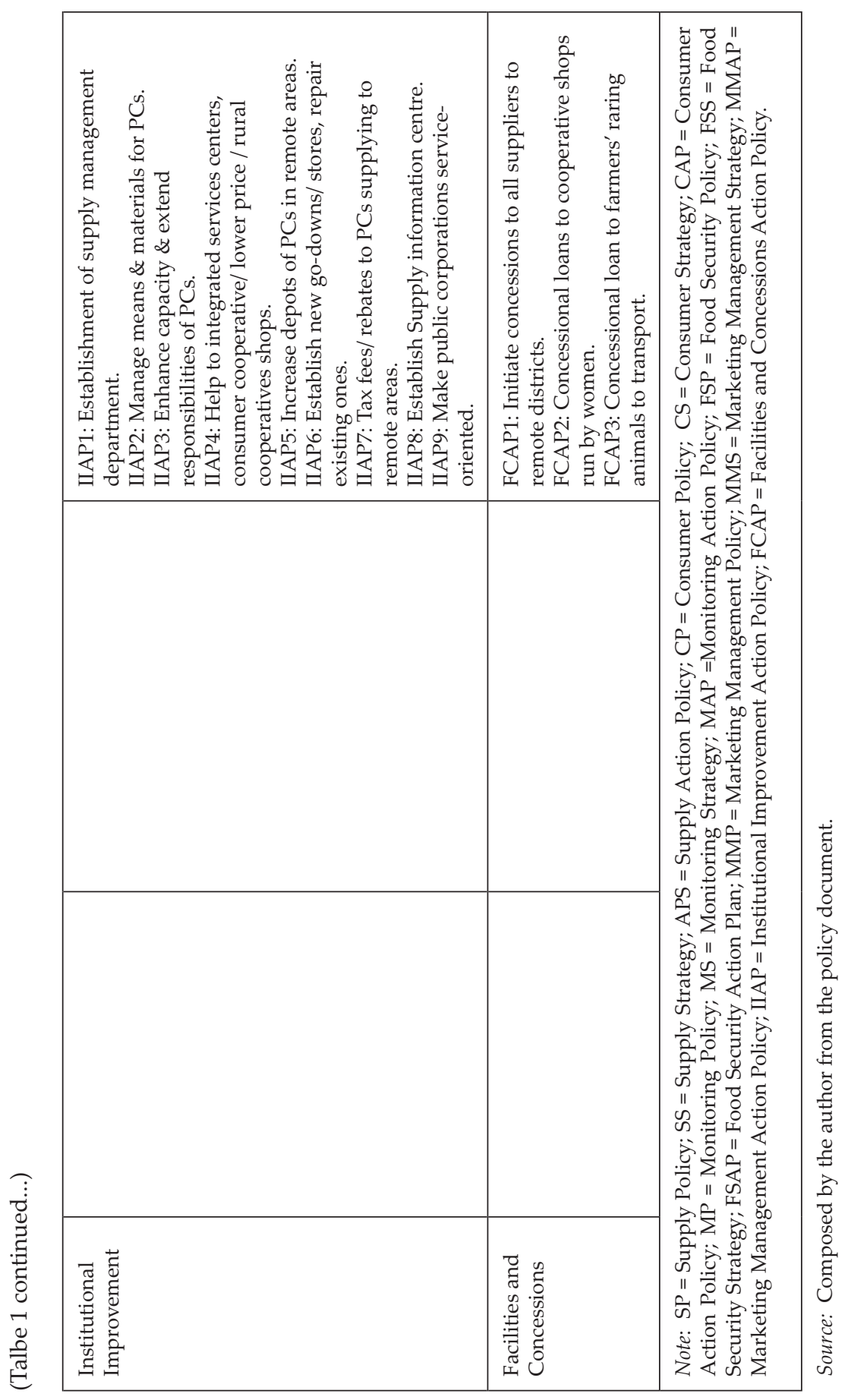


OB 1: SP1, SP2, SP4, SS1, SS2, SS3, SS4, APS1, APS3, APS9, APS11, FSAP4, FSAP5, FSAP10, FSAP11, MMS4, IIAP2, IIAP3, IIAP4, IIAP5, IIAP7, IIAP9, FCAP3.

OB2: SP3, SS4, SS5, SS6, SS9, SS11, APS3, APS4, APS7, APS8, APS10, APS13, CP2, CP3, CP4, CS1, CS2, CS5, CAP1, CAP2, CAP4, CAP5, CAP6, MP3, MAP1, MAP3, MAP4, MAP5, MAP6, FSP3, FSP6, FSS1, FSS2, FSS4, FSAP6, FSAP14, MP2, MMS1, MMS3, MMS4, MMAP1, MMAP3, MMAP4, IIAP4, IIAP8, FCAP1.

OB3: APS2, CP1, CP2, CP4, CS1, CS3, CS4, MP2, MP3, MS1, MS3, MAP1, FSAP7, FSAP8, FSAP9, FSAP12, MP2.

OB4: SS6, SS7, SS8, APS9, APS11, MAP4, MAP6, FSP1, FSP2, FSP3, FSP4, FSP5, FSP6, FSS1, FSS4, FSAP1, FSAP14.

OB5: SP4, SS8, SS9, APS7, APS8, APS9, MS2, FSS2, FSAP2, FSAP14, IIAP4, IIAP5, IIAP7, FCAP1, FCAP3.

OB6: SP3, SS4, SS5, APS4, APS13, CP1, CP2, CP4, CS1, CS2, CS3, CS5, CAP1, CAP3, MP1, MP4, MS3, MAP1, MAP2, MAP4, MAP5, FSP1, MP1, MP2, MMS1, MMS2, MMS3, MMS4, MMS5, MMAP1 - MMAP6.

OB7: There are not any other specific non-competitive market activities stated in the policy document other than related to the objective No. 6 or OB6 so could not be attached any specific policy elements to this particular objective.

\section{ISSUES IN THE IMPLEMENTATION OF THE POLICY}

There are some theoretical as well as practical aspects for successful policy implementation which are described here with reference to the policy under review.

i. For the successful implementation of any public policy some technical aspects would be very important. One of those aspects is the hierarchy of objectives. In the literature of policy analysis 'á five-level optimal/ adequate hierarchy of objectives of public policy has been suggested as (see Aghnihotri, 1995): (1) Aim or Mission; (2) Goals; (3) Policies; (4) Programs; and, (5) Schemes or Projects. However, from the review of the policy document such a scientific hierarchy to be maintained could not be found. Goals and objectives have been well-stated. But looking at the policy elements from strategy and action policy, it could not be differentiated which are the programs and which are the projects that are going to be implemented and what is their time frame as well as how much budget would 
be allotted. This is one of the reasons that the policy could not be evaluated at the time of both pre and post implementation.

ii. From the review of the policy document, consistencies could not be found in the policy elements. The elements from strategy and action policy could not be found to be directly associated with goal and objectives.

iii. For any scientific policy aim, policies, programs and schemes should be well differentiated or demarcated. In other words, level of specifications should be narrowed downed or deepened at each stage so that the objectives could be converted into reality. However, the policy under review lacks such stage-wise specifications. Instead, repetitions could be found at each stage from objectives to action policies.

iv. There are many high-sounding and impressive but vague as well as ambitious elements mentioned in the policy. Just to mention some of those here are - farm and crop development programs in the remote food deficit areas; encourage consumers to consume local products; flow of information about import and storage of goods; determine prices of goods and services on the basis of real costs of production; ban on the export of goods which are scarce locally and so on. Such policy elements are ideal from the theoretical points of view. However, to realize the results as per the objectives concrete working plans and projects would be needed. In the present age of global economy and most of the cases noncompetitive market conditions neither the goods could be supplied at the real cost of production by any of the three sectors nor by their joint efforts. Similarly, the consumers could not be compelled to consume the local goods and services. Ban on the export of locally scarce goods would be in conflict with the policy of export promotion and diversification.

v. The term consumer education used as policy element in the document is ideal. It would increase consciousness of the consumers. But even if the consumers are well taught, it could not regulate the market. Different types of misinformation and misconception frequently capture the minds of the consumers and harm their health in the case of daily necessary goods and services. Consumer education and business ethics or corporate governance are closely interrelated subjects. So, consumer education programs would be effective only if the corporate governance could also remain good. In the absence of the later, the former would just fuel agitations in the consumer mass. 
vi. Fixation of storage ceiling of necessary consumer goods at the times of emergency as well as at the normal time has not been experienced in Nepal. The general people frequently face hardships even at the normal times to get the most necessary goods and services beyond which no justifiable reasons could be placed in. Examples are the voices of the people from the Karnali and other remote areas about unavailability and insufficiency of food every year. Similar has been the case of education and health services in those areas. Supply obstructions are also frequently experienced in the urban areas.

vii. Public policies are formulated and implemented to improve the existing situation. At the time of suddenly arrived emergencies, the responsible institutions or individuals, government, private or cooperatives including NGOs/INGOs should bear additional responsibilities. There are several elements or tools for implementation in the policy document. However, there has been a lack of concrete plans of action which could be operated at the appropriate time.

Ineffectiveness of the supply policy implementation could be exemplified from the situation created by the suddenly arrived difficulties to the Nepalese people by the great earthquake of 12 April, 2015 and the so called Indian blockade imposed from 21 September, 2015. How the general Nepalese people were victimized from those two sudden incidences is out of scope of the present description. People could not travel freely for both short and long distances, schools and hospitals were closed, severe scarcity of daily necessaries was experienced, people have to stay without regular food and shelter, regular services of ambulance and fire brigades were obstructed, live-saving medicines were unavailable only to mention few of the hardships during that period. It was in the name of the blockade and unavailability of the gasoline extreme artificial scarcity and black marketing was experienced (see SHAR, 2016; Transforming Surge Capacity Project, 2015; MASUM, 2016; New Business Age, December, 2015; SAWTEE, 2015). It is in such a situation that the domestic policies should stand strong to protect the general people from difficulties. The adversities could had been minimized if buffer-stocks of minimum quantity of necessary goods had been maintained, go-downs and cold stores constructed as required, roads and air transport were managed, local goods and services substituted the imported ones, cost effective alternative sources of critically necessary goods like gasoline searched, monitoring committees at different levels were activated, storage capacity and standard were fixe and so on as mentioned in the policy. However, food problems at the remote areas has still remain, the earthquake victims are still in the problems without food and shelter, supply obstructions have been frequently experienced, establishment of 
consumer courts and consumer protection fund are limited only in words, markets are rarely intervened to mention few of the issues.

\section{CONCLUSION}

Public policies are formulated and implemented for the overall development of the country. National supply policy is one of those policies formulated to address the aggregate demand of the country. Successful implementation and proper address of suddenly arrived emergencies, both the internal structure of the policy itself and the situation created by the external factors play equally important roles. Current national supply policy of Nepal had not been found to be effective to reach the mentioned goal and produce outputs as desired though the structure seems well constructed in surface. Weak coherence with other related policies could be experienced from the outputs produced by the policy.

\section{References}

Agnihotri, V.K. (1995).An integrated approach to public policy design. In V.K. Agnihotri (Ed.), Public policyanalysis and design. New Delhi: Concept Publishing Company.

Banglar Manabadhikar Suraksha Mancha (MASUM). (2016). Report of fact finding on impact of blockade along Indo-Nepal border. Retrieved from, https://www.forumsia.org/ uploads/wp/2016/07/Fact Finding-Report-on-Npal-Final.pdf

Government of Nepal (GoN), Ministry of Industry, Commerce and Supplies (2069 B.S.). Supply policy (in Nepali). Kathmandu: Author.

Knoepfel, P., Carrue, C., Varone, F., \& Hill, M. (2007). Public policy analysis. Great Britain: The Policy Press.

New Business Age (December, 2015). Business choke under crisis. Retrieved from www. abhiyan.com.np

Reejal, P. R. (2003). Fundamental of public policy analysis. Kathmandu: Pairavi Prakashan.

Sapru, R. K. (1994). Public policy - formulation, implementation and evaluation. New Delhi: Sterling Publishers Private Limited.

South Asians for Human Rights (SHAR). (2016). Nepal blockade - A Humanitarian crisis amidst diplomatic kerfuffle: Fact finding mission report. Retrieved from, www.southasianrights.org/wp-wp- content/uploads/2016/06/Report-onthe-Fact-Finding-Mission-to-Nepal.pdf 
South Asian Watch on Trade Economics and Environment (SAWTEE). (2015). Impact of Nepal's earthquake on food security and livelihood of the urban poor. Retrieved from, www.sawtee.org/Publications/Policy-Brief-31.pdf

Transforming Surge Capacity Project (2015). Nepal earthquake 2015 - review of surge practices. Retrieved from, www.chsalliance.org/Earthquake-2015_Review-ofSurge-Practices.pdf 